\title{
Repensando o Estado brasileiro: em busca de um modelo sustentável
}

\author{
José A. Puppim de Oliveira \\ Fundação Getulio Vargas - FGV/Eaesp e FGV/Ebape
}

Ricardo Corrêa Gomes

Universidade de Brasília - UnB

Editores deste número especial

As crises do Brasil, tanto no governo como na sociedade, vêm exacerbando nos últimos anos os problemas sociais, ambientais e econômicos. Para além das questões econômicas (taxa de juros, inflação etc.) e da "reforma política", que estão no foco da mídia e dos debates políticos e acadêmicos, há muito pouca discussão aprofundada sobre as razões de não conseguirmos avançar na agenda de desenvolvimento nas últimas décadas, que estão justamente no modelo de Estado brasileiro.

As raízes das crises estão no Estado, aqui pensado não só como administração pública nos três níveis de governo, mas, principalmente, em termos de suas relações com a sociedade civil e o sistema político, que estão intimamente relacionadas ao funcionamento daquelas. Muito do que vemos no dia a dia são os sintomas de um Estado esgotado e mal desenhado, que não consegue se adaptar aos anseios da sociedade e às grandes mudanças do Brasil e do mundo. Essa falta de conscientização nos leva, cada vez mais, para uma direção equivocada, à beira de um perigoso abismo de insustentabilidade social.

Os problemas do Estado brasileiro têm uma forte dependência de trajetória e estão bastante arraigados na nossa história (LUSTOSA DA COSTA, 2018). Certas características intrínsecas à formação do Estado pelos portugueses e de nossa tradição ibérica têm remanescido, apesar de todas as reformas weberianas e gerenciais por que passou o Estado brasileiro, que tem sido frequentemente capturado por grupos de interesse. E essa captura não somente gera a corrupção, que tem permanecido alta apesar de todos os esforços para combatê-la (PINHO, 
2018), mas permite que os "direitos republicanos" ${ }^{1}$ dos cidadãos muitas vezes sejam abocanhados pelo aparato legal (BRESSER-PEREIRA, 2018).

Não conseguiremos resolver os graves problemas da sociedade somente com ajustes nas taxas de juros ou com uma reforma política que limite direitos ou representações. Necessitamos discutir uma reforma na estrutura e no funcionamento do Estado, com um amplo debate junto à sociedade, em vez de às escondidas, com decisões a portas fechadas.

Devido às oportunidades proporcionadas pelo bônus demográfico, temos a oportunidade única de fazer os ajustes necessários para que o país busque o desenvolvimento de forma sustentada nas próximas décadas. Talvez esta geração seja a última chance para esses ajustes, antes que o país tenha uma população mais envelhecida, o que dificultaria ainda mais as perspectivas de desenvolvimento de longo prazo.

\section{Repensando o Estado brasileiro}

A nova agenda de sustentabilidade, baseada nos Objetivos de Desenvolvimento Sustentável (ODS), também cria uma grande oportunidade para se repensar o Estado brasileiro com base nos princípios da eficácia, eficiência, equidade, accountability e capacidade de se adaptar às mudanças de contexto nacional e global. Porém existe uma série de desafios políticos, sociais e gerenciais para a administração pública mudar o paradigma de desenvolvimento (GLEMAREC; PUPPIM DE OLIVEIRA, 2012) e implementar essa nova agenda. Entre eles, há a complexidade da busca por um modelo de Estado e mecanismos institucionais para coordenar as políticas públicas para se atingir vários objetivos, que a princípio parecem conflitantes. A administração pública tem vivido, nos últimos anos, uma série de mudanças que trazem oportunidades e ameaças, como a adoção de tecnologia de informação para aumentar sua eficiência. E ainda permanecem vários desafios, como a ética e a pouca coordenação entre as diversas instâncias e políticas públicas (PUPPIM DE OliveIRA; JING; ColLINS, 2015).

No Brasil, alguns temas são fundamentais para balizar as discussões sobre o Estado, os anseios da sociedade e as noções de sustentabilidade para as próximas gerações. Temos diversos temas que emergem nos debates sobre como melhorarmos a capacidade do Estado para responder aos desafios de desenvolvimento.

- O modelo federativo do Brasil. A raiz de muitos problemas na administração pública está na forma como a Federação foi desenhada pela Constituição de 1988. Apesar de ter sido importante para sedimentar a democracia no país, os arranjos

1 “O direito que cada cidadão tem que o patrimônio público seja utilizado para fins públicos” (BRESSER-PEREIRA, 2018). 
administrativos e a democracia em si não criaram uma administração pública compatível com os anseios da sociedade de que o Estado fosse mais eficiente e conseguisse entregar melhores serviços públicos. Temos um modelo federativo onde várias unidades da Federação, principalmente os municípios (e mesmo alguns estados), foram criadas sem ter a capacidade e os recursos necessários para cumprir suas funções na administração pública, como provedores de serviços públicos de qualidade. Temos municípios com mais de 10 milhões de habitantes e outros com menos de mil, mas que têm as mesmas responsabilidades. No final, há uma dependência de recursos das instâncias superiores, via transferências constitucionais ou acertos políticos. Além de criar uma enorme desigualdade entre as unidades e seus habitantes, isso enfraquece as unidades como entes políticos e administrativos autônomos. Como, então, criar um sistema federativo para fortalecer a capacidade das unidades de fornecer serviços públicos de qualidade, proteger a qualidade de vida de seus habitantes e que seja sustentável ao longo prazo?

Temos visto diversos esforços nessa área, mas muitos não têm uma continuidade ou interação com programas já existentes. Isso cria um efeito nem sempre dinâmico na governança dos recursos públicos, o que se expressa nos vários casos de corrupção, que vêm à tona quase que diariamente, e nas capacidades de implementação de política públicas pelos entes subnacionais, com serviços públicos precários em boa parte dos municípios. O "caleidoscópio" na implantação de políticas públicas no federalismo brasileiro faz com que não tenhamos um avanço significativo e homogêneo nas capacidades municipais. Mesmo com os esforços de programas federais para aumentar a capacidade dos municípios, muitos ainda mantêm baixos níveis de capacidade para tratar de questões importantes como educação ou saúde (GRIN; ABRúcIO, 2018).

Assim, em face aos problemas encontrados no atual modelo federativo, uma das prioridades para repensar o Estado brasileiro seria a reformulação desse modelo, para que todos os entes federativos tenham as capacidades de implantação de políticas públicas. Existem vários modelos que poderiam servir de base para a reformulação do arranjo federativo. Por exemplo, o Japão usa um sistema de quatro categorias de governos locais, de acordo com a população e recursos, criando-se critérios para cada categoria. Os municípios mais populosos e com maior capacidade de arrecadar têm mais autonomia, e os menores têm boa parte de suas responsabilidades passadas para as províncias, que são os entes federativos superiores. Existe também um incentivo para que os municípios se amalgamem voluntariamente, para que passem a uma categoria acima e, com isso, tenham mais autonomia e recursos. 
Uma outra referência para se repensar o caso brasileiro poderia ser a Espanha, e seu processo de descentralização. Naquele país, a descentralização se deu de forma gradual. As comunidades autônomas (similares aos nossos estados) recebiam responsabilidades e tinham mais autonomia à medida que estivessem preparadas em termos de capacidade para a gestão pública de determinadas áreas. Assim, algumas áreas tinham responsabilidades limitadas em algumas comunidades, até que tivessem suas capacidades melhoradas.

Existe também uma série de outros modelos e mecanismos que poderiam melhorar o sistema federativo brasileiro. A adoção de profissionais da administração pública certificados atuando como "city managers" (gestores profissionais), por exemplo, poderiam facilitar a melhoria das capacidades dos municípios menores, trazendo profissionais capacitados. Em alguns estados dos Estados Unidos esse arranjo permite que municípios tenham profissionais altamente capacitados, sem vinculação política e conhecedores do sistema público, recrutados no mercado e com contratos de acordo com sua performance. As câmaras de vereadores locais, algumas sem remuneração, são como o conselho para escolher o gestor municipal. Esse sistema também permite uma circulação de pessoas, conhecimento e boas práticas na administração pública, já que alguns profissionais trabalham em vários municípios durante a sua carreira.

- Mecanismos e instituições para relações intergovernamentais. Muitas políticas públicas, principalmente aquelas ligadas à agenda de sustentabilidade, necessitam de um sistema de articulação entre os diversos níveis de governo e administrações públicas, e destes com a sociedade civil, incluindo o setor privado. Porém, não existem mecanismos formais e incentivos para que essas articulações sejam feitas. Há um custo de transação alto para se pensar políticas públicas envolvendo diversos entes federativos, e não há uma hierarquia para decidir e avançar certas ações públicas que são importantes. Como, então, criar um sistema de articulação eficaz entre as unidades da Federação que nos leve em direção à sustentabilidade?

Relações intergovernamentais podem ser formais e informais (PHILLIMORE, 2013). As responsabilidades e grau de autonomia entre os entes federativos são definidos geralmente por um arcabouço legal, como uma constituição. Esses entes operam autonomamente em algumas áreas e interagem entre si em outras (FENNA, 2012). Em muitos casos não existem diretrizes sobre como as interações entre os órgãos da administração pública devem acontecer. Assim, uma coordenação política torna-se necessária para que as burocracias possam interagir e cooperar. Porém, a literatura sobre a interface entre política e burocracia é escassa (DASANDI; ESTEVE, 2017), sendo esta uma área relevante principalmente quando aparecem problemas mais complexos, como mudanças climáticas, que não são previstos na constituição, deixando as interações acontecerem de forma voluntária e informal. 
O caso do Brasil de coordenação intergovernamental entre os diversos níveis de governo dentro do Estado apresenta muitas limitações. O modelo da Federação do Brasil, o federalismo cooperativo, é uma espécie de "jabuticaba" (que só existe aqui). Não existe coordenação formal entre as unidades da Federação, nem de forma vertical, nem de forma horizontal. Esforços de aumentar a capacidade das unidades da Federação por diversos programas têm sido um dos poucos mecanismos para se buscar a coordenação e cooperação entre elas, apesar dos resultados modestos (GRIN; ABRúcIO, 2018). A cooperação é feita de forma voluntária e depende de interação política. As relações intergovernamentais se dão de maneira informal, em alguns casos dificultando a sustentabilidade a longo prazo.

- O sistema político-eleitoral e articulação político-administrativa. Existe uma completa falta de legitimidade do nosso sistema político. Boa parte da população não confia naqueles que a representam, e muitos nem conhecem seus representantes. Há uma grande necessidade de reforma do sistema político para que seja mais eficaz nas decisões, eficiente no uso dos recursos e tenha accountability para com aqueles que representa, além de ter a capacidade de adaptar-se às mudanças da sociedade e do Estado. Porém, diferentemente dos outros debates atuais, há a necessidade de conectarmos o debate do sistema político com as reformas de que o Estado necessita. Assim, como podemos fazer uma reforma do sistema político que gere mais accountability e um Estado mais ágil e eficaz?

No caso brasileiro da articulação político-administrativa, o sistema político precisa ser melhor conectado com o funcionamento da administração pública para uma coordenação vertical e horizontal. Por exemplo, os vereadores não têm uma jurisdição nos municípios, de modo que, por um lado, muitos locais não sabem exatamente quem seria seu representante político para alguma demanda de políticas públicas da prefeitura, e, por outro lado, outros têm mais de um representante. $\mathrm{O}$ mesmo acontece com os deputados, que não têm uma jurisdição definida. Um município muitas vezes não tem ou não sabe quem seria o seu melhor representante no Congresso Nacional ou na Assembleia Legislativa.

Temos um modelo arcaico de planejamento e avaliação de políticas e organizações públicas, o que as torna susceptíveis à corrupção e ineficiência (PupPIM de OliveirA, 2006). Além de sermos pouco transparentes nas decisões públicas, não aprendemos com os erros e não buscamos ajustar e melhorar nossas organizações políticas. Temos um sistema de monitoramento administrativo básico (com o TCU e TCEs), mas com pouca eficácia para corrigir erros, e pouca transparência devido a interferências políticas, sendo ineficaz no combate à corrupção e ao desperdício de recursos públicos. Há pouca interação com a sociedade civil nas decisões importantes. 
Em relação à accountability, no Brasil houve graves problemas de corrupção nos últimos anos. Temos modelos de controle administrativo e social cada vez mais robustos, apesar dos poucos resultados dessa maior accountability (TEIXEIRA et al., 2018). Assim, apesar de as instituições e os mecanismos de combate à corrupção terem avançado na identificação de casos nos últimos anos, o país sofre com um ciclo vicioso de corrupção, e não se vislumbram melhorias no curto e médio prazo (PINHO; SACRAMENTO, 2018).

O ciclo de desarticulação político-administrativo gera diversos problemas no uso de recursos e na provisão de serviços públicos de qualidade. Além dos casos de corrupção, falta um maior e melhor alinhamento do sistema político com o sistema administrativo através de uma reforma política para que as administrações públicas saibam exatamente quem seriam seus articuladores políticos em nível do Legislativo. Esses agentes políticos também poderiam ser responsáveis por articulações horizontais entre os municípios dentro da sua jurisdição política.

Além disto, existiriam outros mecanismos que poderiam reforçar a conexão entre os políticos e a melhoria das administrações públicas. Por exemplo, a exigência de que políticos usem os serviços públicos, como hospitais e escolas, em suas jurisdições iria criar incentivos para que esses serviços pudessem melhorar. O mesmo poderia ser feito com os funcionários públicos, reforçando assim os mecanismos de accountability e evitando uma "saída" do sistema por parte dos principais responsáveis pela qualidade dos serviços públicos, que são os tomadores de decisão e administradores públicos.

- Gestão dos recursos humanos. Talvez o ponto mais importante de um Estado eficaz seja a utilização de seus recursos humanos. Apesar de termos recursos humanos em quantidade e qualidade dentro do Estado, sua utilização e gestão não reflete em qualidade para os serviços públicos. Há diversos problemas em transformar nossos valiosos servidores do Estado em agentes de boas organizações públicas de maneira geral, apesar de existirem ilhas de excelência. Não há uma carreira definida no Estado. Servidores com as mesmas funções e qualificações têm benefícios e carreiras diferentes dentro do Estado, e não há benchmarking com servidores do setor privado. Há também poucas oportunidades de progressão na carreira de maneira horizontal (para outras funções) e pouca flexibilidade dos gestores de usarem os recursos humanos disponíveis. Também há pouco incentivo para inovação e risco. Apesar de geralmente terem benefícios melhores que no mercado, os servidores de carreira estão desmotivados e desmoralizados. Necessitamos de reformas que fortaleçam o sistema meritocrático e uma administração pública com mais autonomia em relação ao sistema político, mas com mais accountability para com a sociedade. Como o Estado pode utilizar melhor seus recursos humanos? 
Uma série de reformas têm sido tentadas para a melhoria da administração pública e seus recursos humanos. Um sistema weberiano atualizado ou a introdução de reformas gerencialistas tiveram impactos limitados (LUSTOSA DA COSTA, 2015). Existe pouca integração entre os sistemas de recursos humanos das diversas esferas da administração pública (COELHO; MENON, 2018). Na realidade poderíamos dizer que existem diversas administrações públicas, com diferenças enormes na gestão e nas condições dos recursos humanos entre os três níveis de governo, entre os três Poderes e entre entes do mesmo nível. Existe pouca ou quase nenhuma mobilidade nos recursos humanos em várias esferas do serviço público. Isso faz com que haja pouca circulação de conhecimento e capacidades dentro do Estado. Na raiz disso está a entidade do concurso público, com seu anacronismo; apesar de ter uma avaliação meritocrática para entrada no serviço, dificulta a gestão, pois dá pouca flexibilidade ao gestor e pouco incentivo aos empregados públicos.

Uma série de reformas seriam necessárias para selecionar e aproveitar melhor os recursos humanos no setor público. Primeiramente, poderia ser criado um conselho de recursos humanos na administração pública para integrar as carreiras nos diversos entes da Federação e englobando os três poderes. Isso ajudaria, por exemplo, a homogeneizar os salários entre diversos órgãos e balizar o salário e benefícios dos servidores com aqueles da iniciativa privada. Também facilitaria a mobilidade horizontal dos servidores entre órgãos públicos, melhorando a circulação de conhecimento. Uma outra medida seria uma mudança no instituto do concurso público, que ainda teria sua relevância, mas não seria a única porta de entrada no serviço público. As habilidades e conhecimentos prévios (CV) das pessoas interessadas em entrar em determinada posição no serviço público poderiam ser o critério de avaliação utilizado por uma comissão de seleção escolhida pelo conselho mencionado acima. Isso daria ao gestor público a chance de escolher a pessoa mais adequada e capacitada para exercer determinada posição, que requer certas habilidades e conhecimentos.

\section{Comentários finais}

O Brasil tem uma certa tradição na área de administração e gestão pública. Nosso campo de políticas públicas tem crescido em quantidade e evoluído em qualidade gradativamente (FARAH, 2018). Temos uma massa crítica importante para a geração de conhecimento tanto na academia como na prática. O país foi o quinto que mais gerou artigos na área de Administração Pública de acordo com a base SCIMago, sendo uma das áreas mais bem colocadas em Ciências Sociais. Da prática, temos gerado diversas inovações, como o orçamento participativo, que foi criado em Porto Alegre em 1988 e agora está em mais de 2.500 cidades em todos os continentes. 
Curitiba desenvolveu o Bus Rapid Transit (BRT), que se espalhou por centenas de cidades em todos os continentes. Porém temos questões estruturais importantes na administração pública que impedem uma aceleração maior das inovações, além daquelas apontadas acima.

Temos um sistema fiscal que é insustentável. O Estado arrecada mais de $35 \%$ do $\mathrm{PIB}$, apesar disto não temos serviços públicos de qualidade. Mais ainda, o déficit fiscal cresce rapidamente e sem perspectivas de mudança a curto e médio prazo. Junte-se a isso a questão do envelhecimento da população a longo prazo. Nosso sistema fiscal tem um peso grande no trabalho e capital produtivo e é extremamente complexo. Precisamos mudar o enfoque para que diluamos os impostos/arrecadação sobre o que seja benéfico para a sociedade e utilizemos o sistema fiscal para avançar com a agenda da sustentabilidade, como, por exemplo, colocando a carga fiscal sobre os combustíveis fósseis e capital improdutivo/especulativo.

A nova agenda de desenvolvimento baseada nos Objetivos de Desenvolvimento Sustentável (ODS), junto com a transição de governos federal e estaduais, fornece uma oportunidade única para buscarmos as micro e macro reformas na administração pública para liderar a busca dos ODS. Já temos visto uma melhoria na governança nos últimos anos, com vários líderes políticos presos condenados como responsáveis por casos de corrupção, coisa pouco comum no passado, mostrando que existe uma independência forte entre os três Poderes. Vemos também mudanças pontuais, mas importantes. Uma nova lei de governança de estatais foi introduzida tentando melhorar o sistema de decisões e accountability, no sentido de controlar casos de corrupção no futuro (FONTES-FILHO, 2018). A democracia tem sido cada vez mais vibrante, permitindo mudanças de governos impopulares e com má gestão, gerando uma accountability política. Porém, ainda temos muito que avançar com o alinhamento das administrações públicas e alinhamento dos sistemas políticos e administrativos. Isso poderá criar as condições de acelerar o processo de desenvolvimento econômico e social no país.

\section{Referências bibliográficas}

BRESSER-PEREIRA, Luiz Carlos. Direitos republicanos e a 'captura' legal do Estado brasileiro. Revista de Serviço Público (neste número), 2018.

CoElHo, Fernando de Souza; MENON, Isabela. A quantas anda a gestão de recursos humanos no setor público brasileiro? Um ensaio a partir das (dis)funções do processo de recrutamento e seleção - os concursos públicos. Revista de Serviço Público (neste número), 2018.

DASANDI, N.; ESTEVE, M. The politics-bureaucracy interface in developing countries. Public Administration and Development, v. 37, p. 231-245, 2017. 
FARAH, Martha. Abordagens teóricas no campo de política pública no Brasil e no exterior: do fato à complexidade. Revista de Serviço Público (neste número), 2018. FEnNA, A. Federalism and intergovernmental coordination. In: Peters, B. G.; Pierre, J. (Eds.). The SAGE Handbook of Public Administration. Los Angeles: SAGE, 2012. p. 750-763.

FERnANDES, Gustavo Andrey Almeida Lopes; Fernandes, Ivan Filipe Lopes Almeida; Carvalho Teixeira, Marco A. Estrutura de funcionamento e mecanismos de interação social nos tribunais de contas estaduais. Revista de Serviço Público (neste número), 2018.

FONTES FILHO, Joaquim Rubens. A governança corporativa em empresas estatais brasileiras frente à Lei de Responsabilidade das Estatais (Lei no 13.303/2016). Revista de Serviço Público (neste número), 2018.

Glemarec, Yannick; PupPIM DE OliveIRA, Jose A. The role of the visible hand of public institutions in creating a sustainable future. Public Administration and Development, v. 32, n. 3, p. 200-214, 2012. DOI: 10.1002/pad.1631

GRIN, Eduardo José; ABRUCIO, Fernando Luiz. Quando nem todas as rotas de cooperação intergovernamental levam ao mesmo caminho: arranjos federativos no Brasil para promover capacidades estatais municipais. Revista de Serviço Público (neste número), 2018.

LUSTOSA DA COSTA, Frederico. História, narrativa e representações da administração pública brasileira. Revista de Serviço Público (neste número), 2018.

PHILlIMORE, J. Understanding intergovernmental relations: key features and trends. Aust. J. Publ. Admin., v. 72, p. 228-238, 2013.

Pinho, José A. G.; SACRAmento, Ana Rita. O círculo vicioso da corrupção no Brasil: limites estruturais e perspectivas de rompimento. Revista de Serviço Público (neste número), 2018.

PupPIM DE OlIVEIRA, Jose A. Desafios do planejamento em políticas públicas: diferentes visões e práticas. Revista de Administração Pública-RAP, v. 40, n. 1, p. 273-88, 2006.

PUPPIM DE OlIVEIRA, J. A.; JING, Y.; ColLINS, P. Public administration for development: trends and the way forward. Public Administration and Development, v. 35, n. 2 p. 65-72, 2015. 
RSP 